CNS Spectrums (2017), 22, 228-235. C Cambridge University Press 2017. This is an Open Access article, distributed under the terms of the Creative Commons Attribution licence (http://creativecommons.org/licenses/by/4.0/), which permits unrestricted re-use, distribution, and reproduction in any medium, provided the original work is properly cited.

\title{
Lurasidone for major depressive disorder with mixed features and irritability: a post-hoc analysis
}

\author{
Alan C. Swann, ${ }^{\prime}$ Maurizio Fava, ${ }^{2}$ Joyce Tsai, ${ }^{3}$ Yongcai Mao, ${ }^{3}$ Andrei Pikalov, ${ }^{3}$ \\ and Antony Loebel ${ }^{3 *}$
}

\footnotetext{
${ }^{1}$ Department of Psychiatry and Behavioral Sciences, Baylor College of Medicine, Houston, Texas

${ }^{2}$ Department of Psychiatry, Massachusetts General Hospital, Boston, Massachusetts

${ }^{3}$ Sunovion Pharmaceuticals Inc., Fort Lee, New Jersey, and Marlborough, Massachusetts
}

Objective. The aim of this post-hoc analysis was to evaluate the efficacy of lurasidone in treating major depressive disorder (MDD) with mixed features including irritability.

Methods. The data in this analysis were derived from a study of patients meeting DSM-IV-TR criteria for unipolar MDD, with a Montgomery-Åsberg Depression Rating Scale (MADRS) total score $\geq 26$, presenting with two or three protocol-defined manic symptoms, and who were randomized to 6 weeks of double-blind treatment with either lurasidone $20-60 \mathrm{mg} / \mathrm{d}(n=109)$ or placebo $(n=100)$. We defined "irritability" as a score $\geq 2$ on both the Young Mania Rating Scale (YMRS) irritability item (\#5) and the disruptive-aggressive item (\#9). Endpoint change in the MADRS and YMRS items 5 and 9 were analyzed using a mixed model for repeated measures for patients with and without irritability.

Results. Some $20.7 \%$ of patients met the criteria for irritability. Treatment with lurasidone was associated with a significant week 6 change vs. placebo in MADRS score in both patients with $(-22.6$ vs. $-9.5, p<0.0001$, effect size $[E S]=1.4)$ and without $(-19.9$ vs. $-13.8, p<0.0001, E S=0.7)$ irritability. In patients with irritable features, treatment with lurasidone was associated with significant week 6 changes vs. placebo in both the YMRS irritability item $(-1.4$ vs. $-0.3, p=0.0012, E S=1.0)$ and the YMRS disruptive-aggressive item $(-1.0$ vs. $-0.3, p=0.0002, E S=1.2)$.

Conclusions. In our post-hoc analysis of a randomized, placebo-controlled, 6-week trial, treatment with lurasidone significantly improved depressive symptoms in MDD patients with mixed features including irritability. In addition, irritability symptoms significantly improved in patients treated with lurasidone.

Received 28 September 2016; Accepted 10 January 2017; First published online 16 March 2017

Key words: Major depressive disorder, irritability, atypical antipsychotics, lurasidone, mixed-features specifier.

\section{Introduction}

Irritability frequently occurs in patients with a diagnosis of major depressive disorder (MDD), with prevalence estimates ranging from 35 to $55 \% .{ }^{1-7}$ As noted in the Diagnostic and Statistical Manual of Mental Disorders, 5th ed. (DSM-5) ${ }^{8}$ many individuals with a diagnosis of MDD report or exhibit irritability. However, irritability is

* Address correspondence to: Antony Loebel, MD, Sunovion Pharmaceuticals Inc., One Bridge Plaza North, Suite 510, Fort Lee, New Jersey 07024.

(Email: antony.loebel@sunovion.com)

This work was supported by Sunovion Pharmaceuticals. Dr. Edward Schweizer, of the Paladin Consulting Group, provided editorial and medical writing assistance, which was funded by Sunovion Pharmaceuticals. not included in the core diagnostic criteria for MDD, nor is it evaluated as a symptom domain in many of the most widely used scales that measure depression severity (e.g., the Montgomery-Åsberg Depression Rating Scale [MADRS], the Hamilton Rating Scale for Depression [HAM-D], the Quick Inventory of Depressive Symptomatology-Self-Report [QIDS-SR ${ }_{16}$ ], and the Patient Health Questionnaire-9 [PHQ-9]).

The presence of irritability in MDD is associated with younger age of onset, increased chronicity and severity, greater impairment in functioning and quality of life, and higher levels of comorbidity-most notably anxiety, impulsivity, and substance use disorders. ${ }^{2,3,5-7,9}$ Some $^{3,10}$ but not all ${ }^{6,7}$ studies of MDD have identified irritability as a risk factor for the development of a bipolar or bipolar mixed diagnosis. 
The presence of irritable features-as part of a spectrum that may include anger, hostility, agitation, and aggressive behavior-has been found to be associated with a significantly delayed or reduced response to standard antidepressants in both unipolar MDD ${ }^{6,11-13}$ and bipolar depression. ${ }^{14,15}$

MDD with mixed features is a common and often severe subtype of major depression that is recognized by the mixed-features specifier in DSM-5. ${ }^{8}$ Prevalence estimates from clinical populations indicate that mixed features occur in at least $25 \%$ of patients with MDD. ${ }^{11,14,16-22}$ Irritability is not included as a criterion for mixed features in DSM-5, in part due to concerns regarding specificity. ${ }^{8}$

Despite the prevalence and prognostic significance of irritability in MDD (with or without mixed features), few prospective studies have examined treatment response in this important clinical population.

Lurasidone is an atypical antipsychotic agent with high affinity for dopamine $\mathrm{D}_{2}\left(K_{i}=1 \mathrm{nM}\right)$ as well as for serotonin $5-\mathrm{HT}_{2 \mathrm{~A}}\left(K_{i}=0.5 \mathrm{nM}\right)$ and $5-\mathrm{HT}_{7}\left(K_{i}=0.5 \mathrm{nM}\right)$ receptors, ${ }^{23}$ and moderate affinity for the $5-\mathrm{HT}_{1 \mathrm{~A}}$ receptor $\left(K_{i}=6.8 \mathrm{nM}\right)$. Lurasidone has demonstrated efficacy in acute and long-term treatment of schizophrenia, ${ }^{24-26}$ as well as in treatment of bipolar depression, both as monotherapy and as an adjunctive therapy with lithium or valproate. ${ }^{27,28}$

The purpose of the present post-hoc analysis was to assess the efficacy of lurasidone in treating MDD patients with mixed features presenting with irritability.

\section{Methods}

The data utilized in our post-hoc analysis were derived from a study designed to evaluate the efficacy of lurasidone for the treatment of patients with MDD presenting with subthreshold hypomanic symptoms (mixed features). The design of the original study is described in detail elsewhere. ${ }^{29}$ In summary, this was a randomized, double-blind, placebo-controlled, 6-week trial that enrolled a total of 209 patients at 18 sites in the United States and 26 sites in Europe. Patients assigned to lurasidone received once-daily flexible dosing in the range of 20 to $60 \mathrm{mg} /$ day.

Diagnosis of MDD was confirmed with the Structured Clinical Interview for DSM-IV-TR Axis I Disorders, Clinical Trials Version (SCID-CT), modified to record the presence of mixed symptoms. ${ }^{30}$ Patients were required to have a score $\geq 26$ on the $\mathrm{MADRS}^{31}$ at both the screening and baseline visits. In addition, patients were required to have on most days, for at least two weeks prior to screening, two or three of the following manic symptoms: elevated or expansive mood, inflated self-esteem or grandiosity, more talkative than usual or feel pressure to keep talking, flight of ideas or racing thoughts, increased energy, increased or excessive involvement in activities with a high potential for negative consequences, and decreased need for sleep. Patients presenting with irritability, distractibility, and psychomotor agitation could be enrolled. However, consistent with the DSM-5 mixed-features specifier, these nonspecific symptoms were not included in the list of eligible manic symptoms required for study entry.

Our study was approved by an institutional review board at each investigational site and was conducted in accordance with the International Conference on Harmonisation of Technical Requirements for Registration of Pharmaceuticals for Human Use's Good Clinical Practice Guidelines, and adhered to the ethical principles of the Declaration of Helsinki. An independent data and safety monitoring board reviewed and monitored patient data throughout the study.

\section{Efficacy assessments}

Efficacy assessment tools included the MADRS, ${ }^{31}$ the Clinical Global Impressions-Severity scale (CGI-S) (which rates overall illness severity on a 7-point scale), ${ }^{32}$ the Hamilton Rating Scale for Anxiety (HAM-A), and the Young Mania Rating Scale (YMRS). ${ }^{33}$ Severity of irritable features was assessed using YMRS items 5 (irritability) and 9 (disruptive-aggressive behavior).

\section{Irritable features subgroup}

Patients were included in the irritable features group if their severity scores were $\geq 2$ on both YMRS items 5 (irritability) and 9 (disruptive-aggressive behavior) at baseline. To further evaluate the prevalence of irritable features at baseline, three secondary definitions of irritability were also utilized: a YMRS item 5 score $\geq 2$ at baseline, a YMRS item 9 score $\geq 2$ at baseline, and the presence of irritability based on the modified SCID-CT administered at the screening visit (without applying YRMS severity criteria).

\section{Statistical analysis}

Efficacy endpoints were assessed for the patients meeting (and not meeting) criteria for irritable features using a mixed model for repeated measures (MMRM) analysis including fixed effects for treatment, visit, irritability subgroup, and pooled center; baseline score as a covariate; and treatment-by-visit, treatmentby-subgroup, subgroup-by-visit, and treatment-by-subgroup-by-visit interaction terms. An unstructured covariance matrix was employed for within-patient correlation. Analysis of efficacy endpoints was not corrected for multiplicity since they were done post hoc. Effect sizes (Cohen's $d$ ) were calculated as the least squares mean difference in the change score divided by 
the pooled standard deviation. Treatment response was defined as a $\geq 50 \%$ reduction from baseline to week 6 in MADRS score, and remission was defined as a week 6 MADRS score $\leq 12$.

\section{Results}

\section{Baseline characteristics}

A total of 43 patients $(20.7 \%)$ had irritable features based on the presence of both YMRS items 5 (irritability) and 9 (disruptive-aggressive behavior) criteria at study baseline; $134(64.4 \%)$ had irritable features based on the presence of the YMRS item 5 (irritability) criterion; $47(22.6 \%)$ had irritable features based on the presence of the YMRS item 9 (disruptive-aggressive behavior) criterion; and 118 (56.7\%) had irritable features based on a modified SCID-CT assessment.

Baseline demographic and clinical characteristicsincluding baseline MADRS, CGI-S, and HAM-A scores-were similar for patients with and without irritable features (based on the presence of both YMRS items 5 and 9 severity criteria) (Table 1 ). For patients with irritable features, the mean YMRS item 5 (irritability) severity score was 3.4 at baseline $(39.5 \%$ with a score $\geq 4$ ), and the mean YMRS item 9 (disruptiveaggressive) severity score was 2.6 at baseline $(18.6 \%$ with a score $\geq 4$ ).

TABLE 1. Baseline demographic and clinical characteristics based on combined YMRS items 5 (irritability) and 9 (disruptive-aggressive behavior) criteria ${ }^{a}$

\begin{tabular}{lrr} 
Characteristic & $\begin{array}{c}\text { Irritable } \\
\text { features } \\
(n=43)\end{array}$ & $\begin{array}{c}\text { Without irritable } \\
\text { features }(n=165)\end{array}$ \\
& $10(23.3)$ & $53(32.1)$ \\
Male, $n$ (\%) & $43.2(13.5)$ & $45.5(11.7)$ \\
Age, years, mean (SD) & $32(74.4)$ & $147(89.1)$ \\
Race, white, $n$ (\%) & & \\
Current no. of mixed features, $n$ (\%) & $24(55.8)$ & $106(64.2)$ \\
2 features & $19(44.2)$ & $59(35.8)$ \\
3 features & $5.1(5.2)$ & $4.0(3.1)$ \\
Lifetime major depressive episodes, & & \\
number, mean (SD) & $1.3(1.8)$ & $1.4(2.3)$ \\
Lifetime psychiatric hospitalizations, & & \\
number, mean (SD) & $4.7(3.2)$ & $3.2(2.5)$ \\
Duration of current major depressive & & \\
episode, months, mean (SD) & & \\
Baseline Scores, mean (SD) & & \\
$\quad$ MADRS total & $34.1(4.8)$ & $4.5(0.6)$ \\
CGI-S & $4.6(0.6)$ & $9.5(3.4)$ \\
YMRS total & $15.1(5.5)$ & $16.5(6.1)$ \\
HAM-A total & $18.4(7.0)$ & \\
\hline
\end{tabular}

CGI-S = Clinical Global Impression-Severity scale; HAM-A = Hamilton Rating Scale for Anxiety; MADRS = Montgomery-Åsberg Depression Rating Scale; $S D=$ standard deviation; YMRS $=$ Young Mania Rating Scale.

${ }^{a}$ Irritable features criteria: YMRS items 5 and 9 scores are both $\geq 2$.
The mean daily dose of lurasidone was $33.0 \mathrm{mg}$ in patients with irritable features and $37.1 \mathrm{mg}$ in patients without irritable features. Completion rates for patients with irritable features treated with lurasidone and placebo were 91.3 and $\mathbf{8 1 . 8 \%}$, respectively, and completion rates in patients without irritable features were 94.2 vs. $86.3 \%$, respectively.

\section{Efficacy}

Combined YMRS items 5 (irritability) and 9 (disruptive-aggressive behavior) criteria

In patients with irritable features, based on the presence of both YMRS items 5 (irritability) and 9 (disruptiveaggressive behavior) criteria at study baseline, treatment with lurasidone was associated with significantly greater improvement at the week 6 endpoint compared to placebo on MADRS and YMRS scores (Table 2) and on CGI-S score (Figure 1A). Effect sizes for week 6 change in MADRS, YMRS, and CGI-S ranged from 1.2 to 1.4 for patients with irritable features. Significant improvement in MADRS score on lurasidone occurred at week 2 and at all subsequent study visits (Figure 2).

In order to evaluate the potential effect of baseline anxiety severity on week 6 improvement in depressive

TABLE 2. Change from baseline to week 6 in efficacy measures based on combined YMRS items 5 (irritability) and 9 (disruptiveaggressive behavior) criteria ${ }^{a}$

$\begin{array}{ccc}\text { DB baseline, } & \text { LS mean } & p \text { value } \\ \text { mean }(S D) & (S E) \text { change } & (E S)\end{array}$

\begin{tabular}{|c|c|c|c|c|}
\hline \multicolumn{5}{|l|}{ MADRS } \\
\hline \multicolumn{5}{|c|}{ Irritable features } \\
\hline Lurasidone & 22 & $34.0(5.2)$ & $-22.6(2.1)$ & \multirow[t]{2}{*}{$<0.0001$} \\
\hline Placebo & 21 & $34.2(4.6)$ & $-9.5(2.2)$ & \\
\hline \multicolumn{5}{|c|}{ Without irritable features } \\
\hline Lurasidone & 86 & $33.0(4.1)$ & $-19.9(1.0)$ & \multirow[t]{2}{*}{$<0.0001(0.7$} \\
\hline Placebo & 79 & $33.1(3.8)$ & $-13.8(1.1)$ & \\
\hline \multicolumn{5}{|l|}{ YMRS total } \\
\hline \multicolumn{5}{|c|}{ Irritable features } \\
\hline Lurasidone & 22 & $15.3(5.6)$ & $-8.5(0.8)$ & \multirow[t]{2}{*}{$0.0003(1.2)$} \\
\hline Placebo & 21 & $14.9(5.5)$ & $-4.5(0.8)$ & \\
\hline \multicolumn{5}{|c|}{ Without irritable features } \\
\hline Lurasidone & 86 & $10.0(3.5)$ & $-6.7(0.4)$ & \multirow[t]{2}{*}{$0.0042(0.5$} \\
\hline Placebo & 79 & $9.0(3.2)$ & $-5.0(0.4)$ & \\
\hline \multicolumn{5}{|l|}{ CGI-Severity } \\
\hline \multicolumn{5}{|c|}{ Irritable features } \\
\hline Lurasidone & 22 & $4.6(0.6)$ & $-2.0(0.2)$ & \multirow[t]{2}{*}{$0.0002(1.2$} \\
\hline Placebo & 21 & $4.6(0.6)$ & $-0.7(0.3)$ & \\
\hline \multicolumn{5}{|c|}{ Without irritable features } \\
\hline Lurasidone & 86 & $4.5(0.6)$ & $-1.8(0.1)$ & \multirow[t]{2}{*}{$0.0067(0.5)$} \\
\hline Placebo & 79 & $4.6(0.6)$ & $-1.3(0.1)$ & \\
\hline
\end{tabular}

CGI-Severity=Clinical Global Impressions-Severity scale; DB = disruptive behavior; $E S=$ effect size; $L S=$ least squares; MADRS = Montgomery-Åsberg Depression Rating Scale; $S D=$ standard deviation; YMRS $=$ Young Mania Rating Scale.

${ }^{\text {a }}$ Irritable features criteria: YMRS items 5 and 9 scores are both $\geq 2$. 


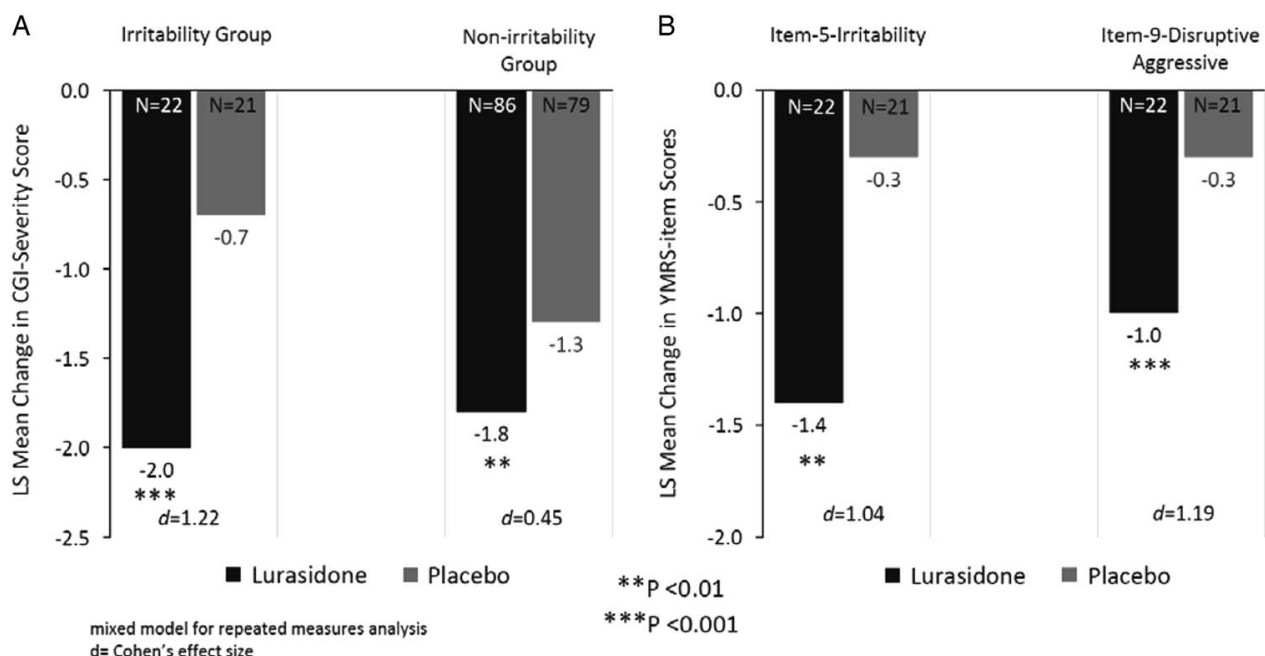

FIGURE 1. (A) Change from baseline to week 6 in CGI-Severity scores for the irritability and non-irritability groups. (B) Change from baseline to Week 6 in YMRS item-5-irritability and item-9-disruptive-aggressive scores for the irritability group.

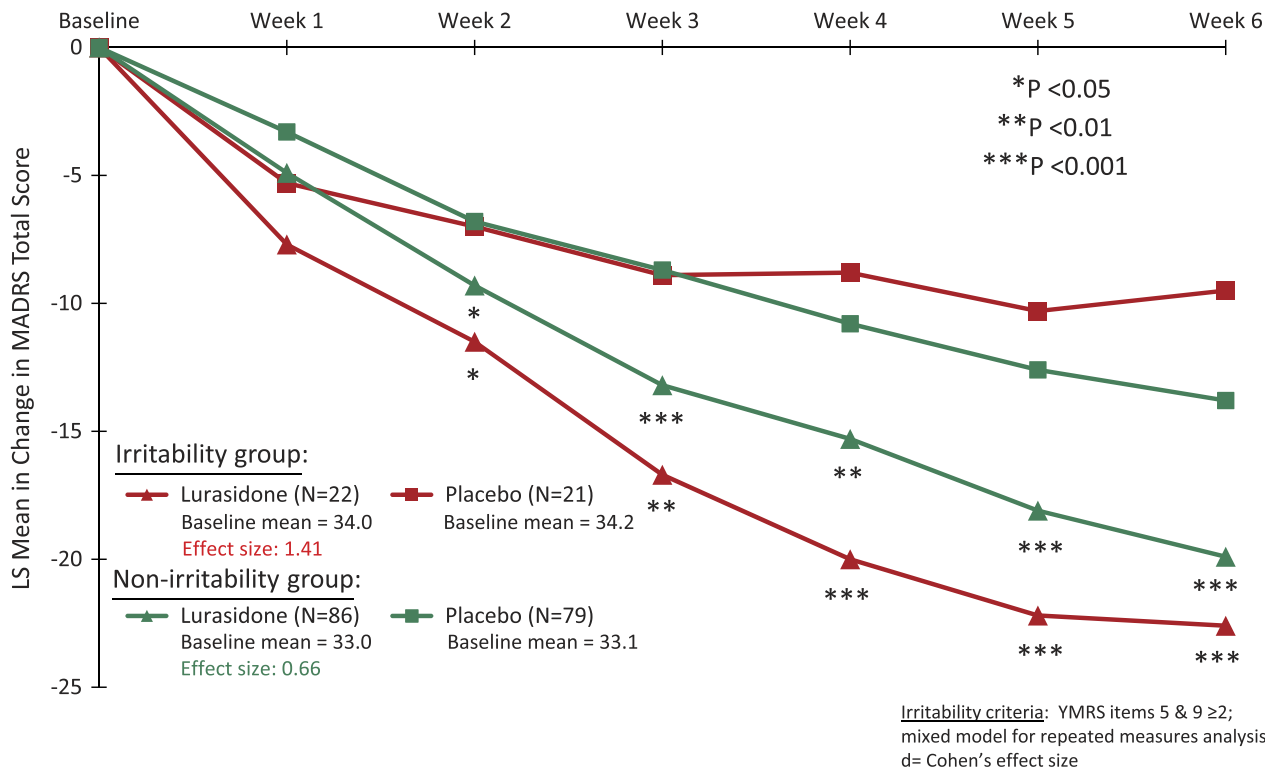

FIGURE 2. Change in MADRS score for the irritability and non-irritability groups.

symptoms, we included baseline HAM-A total score as a covariate in the MMRM model analyzing change from baseline in MADRS score. In patients with irritable features, treatment effect sizes at week 6 were the same (Cohen's $d=1.4$ ) regardless of whether anxiety severity was included as a covariate.

In patients with irritable features, treatment with lurasidone was associated with significantly higher responder rates $(72.7$ vs. $23.8 \%, p=0.017$, number needed to treat $[N N T]=3$; last observation carried forward [LOCF]-endpoint) and remitter rates (63.6 vs. $14.3 \%, p=0.005, N N T=3$ ) compared to placebo.

In patients without irritable features, significant week 6 improvement was observed for lurasidone versus placebo on MADRS, YMRS (Table 2), and CGI-S scores (Figure 1A). Effect sizes for week 6 change in MADRS, YMRS, and CGI-S scores ranged from 0.45 to 0.66 for patients without irritable features. Significant improvement on lurasidone in MADRS scores was observed from week 2 onward (Figure 2). In patients without irritable features, treatment with lurasidone was associated with significantly higher responder rates (62.8 vs. $31.6 \%, p<0.001, N N T=4$; LOCF-endpoint) and remitter rates ( 45.3 vs. $25.3 \%, p=0.002, N N T=5)$ compared to placebo.

In patients with irritable features, based on the presence of the YMRS item 5 (irritability) criterion, treatment with lurasidone was associated with significant 
improvement at week 6 endpoint compared to placebo $(E S=1.0)$; and in patients with irritable features, based on the presence of the YMRS item 9 (disruptiveaggressive behavior) criterion, treatment with lurasidone was associated with significant improvement at the week 6 endpoint compared to placebo $(E S=1.2$; Figure 1B). In the total intention-to-treat (ITT) sample, endpoint improvement on lurasidone was significantly greater than placebo on the item 5 irritability score $(-1.1$ vs. $-0.6, p=0.004)$, but not on the item 9 disruptive-aggressive behavior score $(-0.45$ vs. -0.32 , $p=0.13)$.

\section{YMRS item 5 criterion}

In patients with irritable features based on the presence of the YMRS item 5 (irritability) criterion, treatment with lurasidone was associated with significantly greater week 6 improvement compared to placebo on MADRS $(-20.6$ vs. $-12.1, p<0.0001, E S=0.9)$ and YMRS total scores ( -7.6 vs. $-5.0, p<0.0001, E S=0.7)$; and on the CGI-S (-1.83 vs. $-1.09, p=0.0003, E S=0.7)$.

In patients without irritable features, significant week 6 improvement was observed for lurasidone versus placebo on the MADRS $(-20.3$ vs. $-14.5, p=0.012$, $E S=0.6)$, but not for the YMRS (-6.1 vs. $-4.7, p=0.098$, $E S=0.4)$ or the CGI-S $(-1.83$ vs. $-1.34, p=0.0605$, $E S=0.5)$.

\section{Tolerability}

In patients with irritable features, defined utilizing combined YMRS items 5 and 9 severity criteria, treatment with lurasidone and placebo was associated with the following: rates of all-cause discontinuation: 8.7 vs. $18.2 \%$, respectively; and discontinuation due to adverse events was 4.3 vs. $0 \%$, respectively. In patients without irritable features, treatment with lurasidone and placebo was associated with the following: rates of allcause discontinuation $=5.8$ vs. $13.8 \%$, respectively; and discontinuation due to adverse events $=2.3$ vs. $6.3 \%$, respectively.

In patients with irritable features, the following treatment-emergent adverse events occurred with an incidence $\geq 5 \%$ on lurasidone versus placebo: nausea (8.7 vs. $0 \%$ ) and abdominal discomfort (8.7 vs. $4.8 \%$ ). In patients without irritable features, the following treatmentemergent adverse events occurred with an incidence $\geq 5 \%$ on lurasidone versus placebo: insomnia (7.0 vs. $8.9 \%)$, headache (7.0 vs. $5.1 \%$ ), and nausea (5.8 vs. $2.5 \%$ ).

\section{Discussion}

MDD with mixed features is a common, severe, and

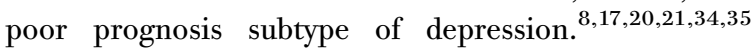

The presence of irritability complicates the clinical picture of MDD with mixed features and may further increase treatment resistance to standard antidepressants. ${ }^{6,11-15}$ In the first prospective placebo-controlled trial in MDD with subthreshold hypomania (mixed features), lurasidone demonstrated significant efficacy in improving the symptoms of depression and subthreshold hypomanic symptoms. ${ }^{29}$ The post-hoc analysis reported here now extends these results by finding lurasidone to have significant efficacy in MDD with mixed features patients who also presented with irritability (defined by the attainment of threshold scores on two irritability-related YMRS items).

Significant improvement in depressive and manic symptoms on lurasidone was observed in patients with irritable features, with notably larger treatment effect sizes for patients with (vs. without) irritability on the MADRS (1.4 vs. 0.7), the CGI-S (1.2 vs. 0.4), and the YMRS (1.2 vs. 0.5). Consistent with these findings, response and remission rates were larger in lurasidonetreated patients with (vs. without) irritable features (response $N N T=3$ vs. 4 ; remission $N N T=4$ vs. 5). Similarly significant improvement was also observed across these efficacy measures in patients with irritability defined using the single YMRS irritability item.

Treatment with lurasidone also significantly improved both irritability (as measured by YMRS item 5) and disruptive-aggressive behavior (as measured by YMRS item 9), with large effect sizes of 1.0 and 1.2, respectively.

These findings are in contrast to previous studies in populations with MDD which reported that the presence of irritable features may be associated with reduced response to standard antidepressants. $6,11,13,14$

It is not clear why the magnitude of the lurasidone treatment effect observed in the current study was larger among patients with irritable features. Larger MADRS effect sizes appeared to be attributable, in part, to reduced improvement on placebo among patients with (vs. without) irritability (MADRS change $=-9.5$ vs. -13.8, respectively), while improvement on lurasidone was somewhat higher among patients with (vs. without) irritability (MADRS change $=-22.6$ vs. -19.9 , respectively). Reduced placebo response in patients with irritable features also appeared to contribute to the larger treatment effect sizes observed for lurasidone on both the CGI-S and YMRS.

Previous studies of MDD have noted higher levels of anxiety in patients presenting with mixed features when compared to MDD patients without mixed features. ${ }^{20,21}$ Mean baseline HAM-A scores in the current MDD-mixed population were relatively high $(\mathrm{HAM}-\mathrm{A}=17.0)$. Anxiety severity at baseline was slightly higher in the group with irritability (18.4) compared to the group without irritability (16.5). Controlling for baseline anxiety severity as a covariate in the MMRM model of MADRS change did not 
alter the week 6 effect size with lurasidone. The relationship between irritability and anxiety symptoms in mixedfeatures patients with MDD warrants further study, in part, to better understand the prognostic and treatment implications of their co-occurrence.

The mechanism for the beneficial effects of lurasidone in this MDD with mixed features and irritability patient population is not known. Preliminary studies have not reported significant efficacy for aripiprazole ${ }^{13}$ or iloperidone $^{36}$ in the treatment of MDD presenting with irritability/anger (but without mixed features). In contrast, treatment with brexpiprazole, administered in combination with a standard antidepressant in an openlabel pilot study, ${ }^{37}$ was found to improve both symptoms of depression and irritability in patients with irritable MDD, but without mixed features. Taken together, these reports suggest that not all atypical antipsychotic agents have efficacy in MDD patients presenting with irritability. The results of the current analyses provide preliminary evidence suggesting that lurasidone, due to its demonstrated antidepressant effects, combined with its moodstabilizing properties, may be an important therapeutic option for the treatment of patients with MDD who present with subthreshold hypomanic (mixed) features including irritability.

Discontinuation rates (all-cause and due to adverse events) associated with lurasidone treatment tended to be higher in the irritability (vs. non-irritability) group. However, all-cause discontinuation rates on lurasidone were markedly lower than placebo in both groups. Rates of discontinuation due to adverse events were higher than placebo for the irritability group, but not for the non-irritability group. The number of treatmentemergent adverse events with an incidence $\geq 5 \%$ was low in both the irritability (nausea, abdominal discomfort) and non-irritability (insomnia, headache, nausea) subgroups, and the rates for these adverse events were all $<10 \%$ and similar to placebo. Overall, the presence of irritability did not markedly influence the tolerability of lurasidone, but the agent was associated with a modest increased risk of study discontinuation due to adverse events.

The analysis reported here has several limitations. Post-hoc analyses are exploratory in nature and require prospective trials for confirmation of findings. The severity threshold used to define irritable features (based on YMRS item scores) may have been too low, resulting in the possible inclusion of some patients without clinically meaningful irritability. Furthermore, a validated scale was not utilized to assess the full spectrum of irritability/hostility/agitation symptoms and behaviors. A related concern is the lack of consensus regarding what constitutes irritability in terms of clinical presentation. It is not clear which subjective symptoms and feelings (e.g., irritability, annoyance, hostility, resentfulness) or outwardly observed behaviors (e.g., agitation, and hot-tempered, angry, or aggressive behavior) should be included in the construct. It is notable that several of the most widely used assessment measures in MDD clinical trials (e.g., the MADRS, the HAM-D, and the QIDS-SR 16 ) do not even include irritability as an item. The relative lack of valid and reliable scales to measure the presence and severity of irritability has been an impediment to research investigating the prevalence of irritability in MDD, its clinical impact, and the effectiveness of treatment, which in turn has encouraged reliance on items from scales validated for other purposes. ${ }^{13,36-38}$

\section{Conclusions}

In this post-hoc analysis of a randomized, placebocontrolled, 6-week trial, treatment with lurasidone significantly improved depressive symptoms in patients with MDD with subthreshold hypomanic (mixed) features and irritability. Irritability and disruptive-aggressive symptoms also showed significant improvement. The magnitude of improvement in both depressive and irritable/aggressive symptoms suggests that lurasidone may be a useful treatment for this MDD mixed-features subpopulation, which is associated with high levels of chronicity, severity, and treatment resistance.

\section{Disclosures}

Dr. Alan Swann's potential conflicts of interest include Elan Pharmaceuticals (research support), Bristol-Myers Squibb (consulting, speaker engagement), Lundbeck (consulting, speaker engagement), Pfizer (consulting, Data Safety Monitoring Board), Teva Pharmaceuticals (consulting, Data Safety Monitoring Board), and Merck (consulting, speaking engagements).

Dr. Maurizio Fava's potential conflicts of interest are as follows: research support from Abbott, Alkermes, American Cyanamid, Aspect Medical Systems, AstraZeneca, Avanir, BioResearch, BrainCells, Bristol-Myers Squibb, CeNeRx BioPharma, Cephalon, Clintara, Covance, Covidien, Eli Lilly, EnVivo, Euthymics Bioscience, Forest, Ganeden Biotech, GlaxoSmithKline, Harvard Clinical Research Institute, Hoffman-LaRoche, Icon Clinical Research, i3 Innovus/Ingenix, Janssen R\&D, Jed Foundation, J \& J, Lichtwer Pharma GmbH, Lorex, Lundbeck, MedAvante, Methylation Sciences, the National Alliance for Research on Schizophrenia \& Depression, the National Center for Complementary and Alternative Medicine, the National Institute on Drug Abuse, the National Institute of Mental Health, Neuralstem, Novartis, Organon, PamLab, Pfizer, Pharmacia-Upjohn, 
Pharmaceutical Research Associates, Pharmavite, PharmoRx Therapeutics, Photothera, Reckitt Benckiser, Roche, RCT Logic, Sanofi-Aventis, Shire, Solvay Pharmaceuticals, Stanley Medical Research Institute, Synthelabo, and Wyeth-Ayerst. He served as a consultant to or on the advisory boards of Abbott, Affectis, Alkermes, Amarin, Aspect Medical Systems, AstraZeneca, Auspex, Avanir, AXSOME Therapeutics, Bayer, Best Practice Project Management, BioMarin, Biovail, BrainCells, Bristol-Myers Squibb, CeNeRx BioPharma, Cephalon, Cerecor, CNS Response, Compellis, Cypress, DiagnoSearch Life Sciences, Dinippon Sumitomo, Dov, Edgemont, Eisai, Eli Lilly, EnVivo, ePharmaSolutions, EPIX, Euthymics Bioscience, Fabre-Kramer, Forest, Forum, GenOmind, GlaxoSmithKline, Grunenthal GmbH, i3 Innovus/Ingenis, Janssen, Jazz, J \& J, Knoll, Labopharm, Lorex, Lundbeck, MedAvante, Merck, MSI Methylation Sciences, Naurex, Nestle Health Sciences, Neuralstem, Neuronetics, NextWave, Novartis, Nutrition 21, Orexigen Therapeutics, Organon, Otsuka, PamLab, Pfizer, PharmaStar, Pharmavite, PharmoRx Therapeutics, Precision Human Biolaboratory, Prexa, PPD, Puretech Ventures, PsychoGenics, Psylin Neurosciences, RCT Logic, Rexahn, Ridge Diagnostics, Roche, Sanofi-Aventis, Sepracor, Servier Laboratories, Schering-Plough, Solvay, Somaxon, Somerset, Sunovion, Supernus, Synthelabo, Takeda, Tal Medical, Tetragenex, TransForm, Transcept, and Vanda. He has had speaking/publishing affiliations with Adamed, Advanced Meeting Partners, the American Psychiatric Association, the American Society of Clinical Psychopharmacology, AstraZeneca, Belvoir Media Group, Boehringer Ingelheim, Bristol-Myers Squibb, Cephalon, CME Institute/Physicians Postgraduate Press, Eli Lilly, Forest, GlaxoSmithKline, Imedex, MGH Psychiatry Academy/Primedia, MGH Psychiatry Academy/Reed Elsevier, Novartis, Organon, Pfizer, PharmaStar, United BioSource, and Wyeth-Ayerst. Dr. Fava has equity holdings in Compellis and PsyBrain, and he receives copyright royalties for the MGH Cognitive and Physical Functioning Questionnaire (CPFQ), the Sexual Functioning Inventory (SFI) scale, the Antidepressant Treatment Response Questionnaire (ATRQ), the Discontinuation-Emergent Signs \& Symptoms (DESS) Scale, the Symptoms of Depression Questionnaire (SDQ), and the SAFER criteria interview, and he has patents for SPCD and for a combination of ketamine and scopolamine in major depressive disorder.

Drs. Joyce Tsai, Yongcai Mao, Andrei Pikalov, and Antony Loebel are employees of Sunovion Pharmaceuticals Inc.

\section{REFERENCES:}

1. Fava M, Rosenbaum JF. Anger attacks in depression. Depress Anxiety. 1998; 8(Suppl 1): 59-63.
2. Perlis RH, Fraguas R, Fava M, et al. Prevalence and clinical correlates of irritability in major depressive disorder: a preliminary report from the Sequenced Treatment Alternatives to Relieve Depression Study. J Clin Psychiatry. 2005; 66(2): 159-166; quiz 147, 273-274.

3. Benazzi F. Possible bipolar nature of irritability in major depressive disorder. J Clin Psychiatry. 2005; 66(8): 1072; author reply 1073.

4. Winkler D, Pjrek E, Kasper S. Anger attacks in depression: evidence for a male depressive syndrome. Psychother Psychosom. 2005; 74(5): 303-307.

5. Perlis RH, Fava M, Trivedi MH, et al. Irritability is associated with anxiety and greater severity, but not bipolar spectrum features, in major depressive disorder. Acta Psychiatr Scand. 2009; 119(4): 282-289. Epub ahead of print Feb 5. Available at: https://www.ncbi. nlm.nih.gov/pmc/articles/PMC3312008/.

6. Fava M, Hwang I, Rush AJ, et al. The importance of irritability as a symptom of major depressive disorder: results from the National Comorbidity Survey Replication. Mol Psychiatry. 2010; 15(8): 856-867. Epub ahead of print Mar 10, 2009. Available at: https://www.ncbi.nlm.nih.gov/pmc/articles/PMC3012558/.

7. Judd LL, Schettler PJ, Coryell W, et al. Overt irritability/anger in unipolar major depressive episodes: past and current characteristics and implications for long-term course. JAMA Psychiatry. 2013; 70(11): 1171-1180. Available at: http://jamanetwork.com/ journals/jamapsychiatry/fullarticle/1737169.

8. American Psychiatric Association. Diagnostic and Statistical Manual of Mental Disorders, 5th ed. Washington, DC: American Psychiatric Association; 2013.

9. Zisook S, Rush AJ, Albala A, et al. Factors that differentiate early vs. later onset of major depression disorder. Psychiatry Res. 2004; 129(2): 127-140.

10. Benazzi F, Akiskal H. Irritable-hostile depression: further validation as a bipolar depressive mixed state. J Affect Disord. $2005 ; \mathbf{8 4}(2-3)$ : 197-207.

11. Perlis RH, Uher R, Ostacher M, et al. Association between bipolar spectrum features and treatment outcomes in outpatients with major depressive disorder. Arch Gen Psychiatry. 2011; 68(4): 351-360. Epub ahead of print Dec 6, 2010. Available at: https://www.ncbi. nlm.nih.gov/pmc/articles/PMC3794668/.

12. Judd LL, Schettler PJ, Akiskal H, et al. Prevalence and clinical significance of subsyndromal manic symptoms, including irritability and psychomotor agitation, during bipolar major depressive episodes. J Affect Disord. 2012; 138(3): 440-448. Epub ahead of print Feb 6. Available at: https://www.ncbi.nlm.nih.gov/pmc/ articles/PMC3677770/pdf/nihms468685.pdf.

13. Fisher LB, Fava M, Doros GD, et al. The role of anger/hostility in treatment-resistant depression: a secondary analysis from the ADAPT-A study. J Nerv Ment Dis. 2015; 203(10): 762-768.

14. Pae CU, Vohringer PA, Holtzman NS, et al. Mixed depression: a study of its phenomenology and relation to treatment response. J Affect Disord. 2012; 136(3): 1059-1061.

15. Yuen LD, Shah S, Do D, et al. Current irritability associated with hastened depressive recurrence and delayed depressive recovery in bipolar disorder. Int J Bipolar Disord. 2016; 4(1): 1-8. Available at: https://www.ncbi.nlm.nih.gov/pmc/articles/PMC4967068/pdf/ 40345_2016_Article_56.pdf.

16. Judd LL, Akiskal HS. The prevalence and disability of bipolar spectrum disorders in the US population: re-analysis of the ECA database taking into account subthreshold cases. J Affect Disord. 2003; 73(1-2): 123-131.

17. Angst J, Cui L, Swendsen J, et al. Major depressive disorder with subthreshold bipolarity in the National Comorbidity Survey Replication. Am J Psychiatry. 2010; 167(10): 1194-1201. Epub 2010 Aug 16. Available at: https://www.ncbi.nlm.nih.gov/pmc/ articles/PMC3145248/. 
18. Angst J, Azorin JM, Bowden CL, et al. Prevalence and characteristics of undiagnosed bipolar disorders in patients with a major depressive episode: the BRIDGE study. Arch Gen Psychiatry. 2011; 68(8): 791-798. Available at: http://jamanetwork.com/journals/ jamapsychiatry/fullarticle/1107421.

19. Benazzi F, Akiskal HS. Psychometric delineation of the most discriminant symptoms of depressive mixed states. Psychiatry Res. 2006; 141(1): 81-88.

20. Hoertel N, Le Strat Y, Angst J, et al. Subthreshold bipolar disorder in a US national representative sample: prevalence, correlates, and perspectives for psychiatric nosography. J Affect Disord. 2013; 146(3): 338-347. Epub ahead of print Oct 3, 2012.

21. McIntyre RS, Soczynska JK, Cha DS, et al. The prevalence and illness characteristics of DSM-5-defined "mixed feature specifier" in adults with major depressive disorder and bipolar disorder: results from the International Mood Disorders Collaborative Project. $J$ Affect Disord. 2014; 172: 259-264. Epub ahead of print Oct 12.

22. Perugi G, Angst J, Azorin JM, et al. Mixed features in patients with a major depressive episode: the BRIDGE-II-MIX study. J Clin Psychiatry. 2015; 76(3): e351-e358.

23. Ishibashi T, Horisawa T, Tokuda K, et al. Pharmacological profile of lurasidone, a novel antipsychotic agent with potent 5-hydroxytryptamine $\left(5-\mathrm{HT}_{7}\right)$ and $5-\mathrm{HT}_{1 \mathrm{~A}}$ receptor activity. J Pharmacol Exp Ther. 2010; 334(1): 171-181. Available at: http://jpet.aspetjournals.org/content/334/1/171.long.

24. Nakamura M, Ogasa M, Guarino J, et al. Lurasidone in the treatment of acute schizophrenia: a double-blind, placebo-controlled trial. J Clin Psychiatry. 2009; 70(6): 829-836. Epub ahead of print Jun 2.

25. Meltzer HY, Cucchiaro J, Silva R, et al. Lurasidone in the treatment of schizophrenia: a randomized, double-blind, placebo- and olanzapine-controlled study. Am J Psychiatry. 2011; 168(9): 957-967. Epub ahead of print Jun 15. Available at: http://ajp. psychiatryonline.org/doi/pdf/10.1176/appi.ajp.2011.10060907.

26. Loebel A, Cucchiaro J, Xu J, Sarma K, Pikalov A, Kane JM. Effectiveness of lurasidone vs. quetiapine XR for relapse prevention in schizophrenia: a 12-month, double-blind, noninferiority study. Schizophr Res. 2013; 147(1): 95-102. Epub ahead of print Apr 11. Available at: http://www.schres-journal.com/article/S0920-9964 (13)00159-X/pdf.

27. Loebel A, Cucchiaro J, Silva R, et al. Lurasidone monotherapy in the treatment of bipolar I depression: a randomized, double-blind, placebo-controlled study. Am J Psychiatry. 2014; 171(2): 160-168.
Available at: http://ajp.psychiatryonline.org/doi/pdf/10.1176/appi. ajp.2013.13070984.

28. Loebel A, Cucchiaro J, Silva R, et al. Lurasidone as adjunctive therapy with lithium or valproate for the treatment of bipolar I depression: a randomized, double-blind, placebo-controlled study. Am J Psychiatry. 2014; 171(1): 169-177. Available at: http://ajp. psychiatryonline.org/doi/pdf/10.1176/appi.ajp.2013.13070985.

29. Suppes T, Silva R, Cucchiaro J, et al. Lurasidone for the treatment of major depressive disorder with mixed features: a randomized, double-blind, placebo-controlled study. Am J Psychiatry. 2016; 173(4): 400-407. Epub ahead of print Nov 10, 2015.

30. First MB, Williams J, Spitzer RL, et al. Structured Clinical Interview for DSM-IV-TR Axis I Disorders, Clinical Trials Version (SCID-CT). New York: Biometrics Research, New York State Psychiatric Institute; 2007.

31. Montgomery SA, Åsberg M. A new depression scale designed to be sensitive to change. Br J Psychiatry. 1979; 134: 382-389.

32. Guy W. ECDEU Assessment Manual for Psychopharmacology. Publication no. ADM 76-338. Washington, DC: U.S. Department of Health, Education, and Welfare; 1976: esp. 218-222.

33. Young RC, Biggs JT, Ziegler VE, et al. A rating scale for mania: reliability, validity, and sensitivity. Br J Psychiatry. 1978; 133: 429-435.

34. Smith DJ, Forty L, Russell E, et al. Sub-threshold manic symptoms in recurrent major depressive disorder are a marker for poor outcome. Acta Psychiatr Scand. 2009; 119(4): 325-329. Epub ahead of print Dec 16, 2009.

35. Nusslock R, Frank E. Subthreshold bipolarity: diagnostic issues and challenges. Bipolar Disord. 2011; 13(7-8): 587-603. Available at: https://www.ncbi.nlm.nih.gov/pmc/articles/PMC3397420/.

36. Ionescu DF, Fava M, Kim DJ, Baer L, Shelton RC, Cusin C. A placebo-controlled crossover study of iloperidone augmentation for residual anger and irritability in major depressive disorder. Ther Adv Psychopharmacol. 2016; 6(1): 4-12. Available at: https://www.ncbi. nlm.nih.gov/pmc/articles/PMC4749740/.

37. Fava M, Ménard F, Davidsen CK, Baker RA. Adjunctive brexpiprazole in patients with major depressive disorder and irritability: an exploratory study. J Clin Psychiatry. 2016; 77(12): 1695-1701. Available at: http://www.psychiatrist.com/jcp/article/ Pages/2016/v77n12/v77n1225.aspx.

38. Khan SA, Revicki DA, Hassan M, et al. Assessing the reliability and validity of the Sheehan Irritability Scale in patients with major depressive disorder. J Clin Psychiatry. 2016; 77(8): 1080-1086. 